The Agriculturists 16(2): 15-24 (2018) ISSN 2304-7321 (Online), ISSN 1729-5211 (Print)

A Scientific Journal of Krishi Foundation

Indexed Journal

DOI: http://dx.doi.org/ 10.3329/agric.v16i02.40339

Impact Factor: 0.568 (GIF, 2015)

\title{
Antifungal Efficacy of Plant Oils Containing Thymol and Carvacrol in Controlling Botrytis cinerea, the Causal Agent of Grape (Vitis vinifera) Gray Mould
}

\author{
Zaker M. ${ }^{1 *}$ and Zaker L. ${ }^{2}$ \\ ${ }^{1}$ Department of Plant Protection Research, Shahrood Agricultural Research Center, Shahroor, Iran \\ ${ }^{2}$ Graduated Student of Laboratory Science, Tehran University of Medical Sciences, Tehran, Iran \\ *Corresponding author and Email: masoudzaker35@gmail.com
}

Received: 26 September 2018

Accepted: 25 December 2018

\begin{abstract}
The efficacy of a large number of plant extracts and essential oils in controlling plant diseases has been proven worldwide. Botrytis cinerea has attacked a wide host range causing severe loss in the field and at storage. In this study the antifungal efficacy of essential oils of three medicinal plants namely wild marjoram (Zataria multifolia), wild savory (perennial) (Satureja mutica) and savory (annual) (Satureja hortensis) possessing these compounds at three concentrations: 50, 100 and $200 \mathrm{ppm}$ were evaluated in controlling the mycelial growth, spore germination and germ tube elongation of $B$. cinerea. All treatments except savory (annual) essential oil at $50 \mathrm{ppm}$ showed significant differences with the control in inhibiting the mycelial growth as well as spore germination and germ tube elongation of $B$. cinerea $(\mathrm{p}=0.01)$. It was also noted that wild marjoram at $100 \mathrm{ppm}$ and wild savory (perennial) essential oils at $200 \mathrm{ppm}$ could completely (100\%) inhibit the growth of the fungus. Essential oils from wild marjoram and wild savory had higher antifungal activity than annual savory. Their suitable formulations could be prepared and used as safe alternatives for controlling moulds of horticultural products during storage.
\end{abstract}

Keywords: Antifungal potential, essential oils, grape, gray mould.

\section{Introduction}

Grape is one of the main horticultural products of temperate regions in Iran. About 300000 hectare of land is under its cultivation with an average yield of about 25 tons/ha. A variety called Red Fakhri (thick skinnd) is grown in norther Iran with a good storage property. This product is harvested and kept in cold storage (about $1^{\circ} \mathrm{C}$ ) during the winter and gradually sold until the spring (Ahmadi et al., 2016).

Grape gray mould caused by Botrytis cinerea Pers. Ex. Fr. is one the most important decaying fungi of this product in the wine yards and also in the store leading to rotting of the product (Elad et al., 2007). Among several postharvest diseases of table grapes (Vitis vinifera) occurring during storage, gray mold is a particularly, severe disease because the causal agent, $B$. cinerea, grows at temperature as low as $0^{\circ} \mathrm{C}$. Other postharvest diseases, caused by Penicillium spp. and Aspergillus spp., also often lead to deterioration of table grapes after harvest (Shin et al., 2014). In Iran, during the storage period $B$. cinerea. causes more damage than those caused by Penicillium spp. (Ghafari et al., 2011; Jalili-Marandi et al., 2010). 
Extracts and essential oils of a huge number of plants possess chemical compounds such as alkaloids, tannins, quinines, phenolic compounds and phytoalexins with their approved antifungal efficacy (Fawcett and Spencer, 1966). The use of plant essential oil compounds such as thymol and linalool, to reducing postharvest diseases in several kinds of fruits, including table grapes and oranges, has received much attention in European countries.

Results of a research showed that among 21 plant essential oils, the thyme (Thymus capitatus) essential oil at $1 \%$, completely controlled the mycelial growth as well as spore germination of $B$. cinerea under in vitro condition while essential oils of clove (Syzygium aromaticum) and an Australian meant (Prostanthera rotundifolia) had fungistatic activity of 93 and $65 \%$ respectively (Antonov et al., 1998). Siripornvisal et al. (2009) evaluated four medicinal plant essential oils against $B$. cinerea and reported that in a modified in-vitro micro-atmospheric test, vapors of clove, cinnamon and lemongrass oils exhibited strong inhibitory effects on $B$. cinerea, with minimal inhibitory quantity (MIQ) equal to $15 \mu \mathrm{L}$ while the vapors of galingale oil exhibited weaker inhibitory effect with MIQ of $25 \mu \mathrm{L}$. They reported that among four medicinal plant essential oils, clove, cinnamon and lemongrass oils exhibited fungicidal effect on the pathogen, while galingale oil exhibited some fungistatic properties and finally they concluded that the clove, cinnamon and lemongrass essential oils might be used as alternative options for the control of gray mould on postharvest organic strawberry fruits especially as a natural fumigant in closed container or packaging (Siripornvisal et al., 2009).

In a survey, antifungal activity of 13 medicinal plant essential oils were studied against apple gray mold through pour plate method and production of volatile compounds. The results showed that essential oils of anise, cumin, caraway, ammin, pennyroyal, thyme and cinnamon at concentrations of 250, 500, 750 $\mu \mathrm{L} / \mathrm{L}$. had a significant effect against $B$. cinerea on PDA culture. By the volatile compounds production method, cumin, ammin, pennyroyal, dill, cinnamon, anise and caraway essential oils showed the most inhibitory effect and the others illustrated somewhat fungistatic power. (Behdani et al., 2012). Shin et al. (2014) reported that thymol $(30 \mu \mathrm{g} / \mathrm{mL})$ and linalool $(120 \mu \mathrm{g} / \mathrm{mL})$ significantly inhibited the mycelial growth and conidia germination of $B$. cinerea. The occurrence rate of gray mould and other unknown fungi were significantly reduced by fumigation with $30 \mu \mathrm{g} / \mathrm{mL}$ thymol in several table grape cultivars, such as Campbell early, Muscat Bailey A, Sheridan, and Geobong. However fumigation at such rate had no influence on the sugar content and hardness of grapes, but significantly reduced the fungal infection. Therefore, they suggested that 30 $\mu \mathrm{g} / \mathrm{mL}$ thymol could be utilized to reduce deterioration of grapes caused by gray mold and other fungal infections during long-term storage. Mermer-Dogu and Zobar (2014) studied the effect of 7 different essential oils of grape seed (Vitis vinifera), thyme (Thymus sp.), rosemary (Rosmarinus officinalis), ozone oil (Olea europaea), peppermint (Mentha piperita), basil (Ocimum basilicum) and sage (Salvia spp.) against $B$. cinerea and reported that in term of priority, the thyme, peppermint and rosemary oils were effective against this pathogen.

Sesan et al. (2015) working on effect of several plant extracts of savory (Satureja hortensis), garlic (Allium sativum), peppermint (Mentha piperita), rosemary (Rosmarinus officinalis), wormwood (Artemisia dracunculus), yarrow (Achillea millefolium), and hyssop (Hyssopus officinalis) against $B$. cinerea of blackcurrant (Ribes nigrum L.) reported that 10 to $20 \%$ concentrations of savory, garlic, peppermint and hyssop extracts could control the pathogen between 80 to $100 \%$, while the lowest antibotrytis activity or no efficiency was noticed by yarrow, wormwood, wormwood and rosemary extracts when even applied at $20 \%$. In another study, savory (Satureja hortensis), wild marjoram (Zataria multiflora) and ajwain 
(Carum copticom) essential oils were tested in vitro (on PDA) and in vivo (dipping inoculated fruit into essential oil solutions) against strawberry gray mold (B. cinerea) and authors concluded that a $200 \mathrm{ppm}$ concentration of savory, wild marjoram and ajwain were able to effectively control the growth of the fungus in both methods (Etemadi et al., 2012).

In the present study, the efficacy of wild marjoram (Zataria multifolia), annual savory (Satureja hortensis) and perennial or wild savory (S. mutica) essential oils at three concentrations (50, 100 and $200 \mathrm{ppm})$ in inhibiting the mycelial growth, spore germination and germ tube elongation of grape gray mould causal agent were compared.

\section{Materials and Methods}

\subsection{Essential oil extraction}

Matured plant parts of wild marjoram, annual savory and perennial savory were washed and dried in shade at room temperature. They were then powdered by grinder and $100 \mathrm{~g}$. of each were mixed with $500 \mathrm{ml}$ distilled water. Essential oils were extracted by steam distillation method using a clevenger apparatus for $5 \mathrm{hr}$. Measurements of essential oils were performed using a QP-5050A (Shimadzu) gas chromatograph coupled with a VG Autospect Mass Spectrometer (MS) at $70 \mathrm{eV}, 40-550 \mathrm{amu}$ with a fused silica capillary column using helium as a carrier gas and with temperature programming from $60{ }^{\circ} \mathrm{C} / 5$ minutes to $300{ }^{\circ} \mathrm{C} / 2$ minutes. The MS was operated using an interface temperature of $240{ }^{\circ} \mathrm{C}$, and an electron impact ionization of $70 \mathrm{eV}$ with a scan mass range of $40-350 \mathrm{~m} / z$ (sampling rate of $1.0 \mathrm{scan} / \mathrm{s}$ ). Identification of the compounds was conducted by comparing their linear retention indices (LRI) with literature values and their mass spectral data with those from the MS data system. Linear retention indices were calculated using GC data of a homologous series of saturated aliphatic hydrocarbons $\left(\mathrm{C}_{8}\right.$ to $\left.\mathrm{C}_{40}\right)$ separated on the same column using the same conditions as for GC analysis of the essential oils (Adams, 2007).
These essential oils prepared as $100 \%$ pure materials were kept in cold storage for further studies.

\subsection{Preparation of selective media for isolation of $B$. cinerea from infected grape berries}

For preparation of Botrytis selective medium, $1 \mathrm{~g}$ NaNO3, 1.2 g K2HPO4, 0.2 g $\mathrm{MgSO}_{4} .7 \mathrm{H}_{2} \mathrm{O}$, $0.15 \mathrm{~g} \mathrm{KCl}, 20 \mathrm{~g}$ glucose and $25 \mathrm{~g}$ agar were added to $1 \mathrm{~L}$ of distilled water and autoclaved at $121^{\circ} \mathrm{C}$ for $20 \mathrm{~min}$. The prepared medium was cooled to $60^{\circ} \mathrm{C}$ and then under sterilized condition, $0.015 \mathrm{~g}$ PCNB, $0.01 \mathrm{~g}$ Maneb, $0.05 \mathrm{~g}$ Chloramphenicol, $2.2 \mathrm{~g} \mathrm{CuSO}_{4}$ and $5 \mathrm{ml}$ of tannic acid were added to it. The $\mathrm{pH}$ of the medium was adjusted to 5.5 with $1 \mathrm{~N} \mathrm{NaOH}$ (Kritzman and Netzer, 1978).

\subsection{Isolation and purification of B. cinerea}

Infected grape bunches were collected from grape wine yards and were transferred to the laboratory. They were thoroughly washed in running water, and then small berry portions from in between healthy and affected parts were separated and were surface sterilized with sodium hypocheloride $0.5 \%$ for $30 \mathrm{sec}$. After washing 2-3 times with sterilized distilled water they were dried in between sterilized filter papers and cultured in Botrytis selective medium as mentioned by Kritzman and Netzer (1978). After 3-4 days, using hyphal tip method, small portions of newly growing hypha with medium were transferred to petri plates containing potato dextrose agar (PDA) medium and kept at $20{ }^{\circ} \mathrm{C}$ in an incubator for its proper growth. Petri plates were then sealed with parafilm and kept at $4{ }^{\circ} \mathrm{C}$ in a refrigerator for further use.

\subsection{Pathogenicity test}

Botrytis spores were collected from 2 weeks old culture grown on PDA into an Erlenmayer flask filled with sterilized distilled water using a sterilized scalpel. The Erlenmayer flask was then kept on a shaker for $20 \mathrm{~min}$ to gain a homogenized spore suspension. Using a hemocytometer, the spore concentration was adjusted to $10^{5}$ spores $/ \mathrm{mL}$. Before inoculating the grape berries with spore suspension, they 
were surface sterilized with Ethanol $70 \%$ and then slightly injured with a sterilized needle. Inoculated grape berries were then kept inside sterilized desiccator at $20{ }^{\circ} \mathrm{C}$ and were inspected daily for appearance of gray mold symptoms. After appearance of symptoms and production of abundant number of spores the causal agent was reisolated and identified using standard identification key (Beever and Weeds, 2004) to fulfill the Koch's postulates.

\subsection{Effect of different essential oil concentrations on mycelial growth of $B$. cinerea}

For estimating the antifungal effect of three concentrations $(50,100$ and $200 \mathrm{ppm})$ of tested essential oils on mycelial growth of the fungus, poisoned food technique was employed (Soylu et al., 2010). Briefly the technique is, after cooling the autoclaved PDA up to $50{ }^{\circ} \mathrm{C}$, under sterilized condition, the estimated amount of essential oils was added to the flasks of the medium. For gaining a homogenous mixture of the culture medium and the essential oil about $0.5 \%$ of Tween-80 was added and shaken gently. After pouring the prepared medium into petri plates, 5 $\mathrm{mm}$ discs of 7 days old $B$. cinerea cut with a sterilized borer was placed at the centre of petri plates. For the control only the Tween- 80 was added into PDA plates. Three replications were used for each treatment and inoculated petri plates were kept inside an incubator at $20{ }^{\circ} \mathrm{C}$.
After 6 days when the fungal growth reached at the edge of the petri plates, the mycelial growth on the medium in different petri plates was measured horizontally and vertically and was noted down.

\subsection{Effect of different essential oil concentrations on spore germination and germ tube elongation of $B$. cinerea}

In this section the method of spore germination assay used by Soylu et al. (2010) was employed. A very thin layer of PDA as prepared previously were poured in petri plates so that germinating spores were easily seen under light microscope. About $150 \mu \mathrm{l}$ of spore suspension of the fungus at about $10^{4}$ spores $/ \mathrm{mL}$ were spread over the thin layer of petri-plate and were kept inside the incubator at $20^{\circ} \mathrm{C}$ for $12 \mathrm{hr}$. Three drops of lactophenol cotton blue were spread over the petri plates. About 100 spores were observed and their germ tubes' length was measured. Three replications were used for each treatment and in the case of control only Tween-80 was used.

\subsection{Data analysis}

Experiments were conducted using 10 treatments (Table 1) and three replications in a completely randomized design. Data were analyzed using Mstat-C software and means were compared using Dunkan's multiple range test at 1 and 5\% level of significance.

Table 1. Medicinal plants with the concentration of essential oil used as treatments

\begin{tabular}{llc}
\hline Treatment code & Plant & Essential oil concentration (ppm) \\
\hline 1 & Wild marjoram & 50 \\
2 & Wild savory & 50 \\
3 & Savory & 50 \\
4 & Wild marjoram & 100 \\
5 & Wild savory & 100 \\
6 & Savory & 100 \\
7 & Wild marjoram & 200 \\
8 & Wild savory & 200 \\
9 & Savory & 200 \\
10 & Control (check) & ---- \\
\hline
\end{tabular}




\section{Results and Discussion}

\subsection{Amount of Essential oils and their main compounds}

The percentage of the main compounds of wild marjoram, wild savory (perennial) savory (annual) essential oils are shown in Table 2.

\subsection{Pathogenicity test of $B$. cinerea on grape berries}

After conducting the pathogenicity test on grape berries (Var. Askari), (Fig. 1), the re-isolated fungus was identified as $B$. cinerea with the use of standard identification key provided by Beever and Weeds (2004).

\subsection{Effect of different essential oil concentrations on mycelial growth of $B$. cinerea}

All treatments except $50 \mathrm{ppm}$ concentration of savory, essential oil had significant differences in reducing the mycelial growth of $B$. cinerea compared to control $(\mathrm{p}=0.01)$. In these test essential oils of wild marjoram and wild savory at $200 \mathrm{ppm}$ completely (100\%) inhibited the mycelial growth of the fungus although at 100 ppm some mycelial growth was observed. Among the plants wild marjoram and wild savory performed better antifungal activity as compared to savory (Table 3 and Fig. 2).

\subsection{Effect of different essential oil concentrations on spore germination and germ tube elongation of $B$. cinerea}

In this experiment, the spore germination of $B$. cinerea was reduced by different concentrations of all three medicinal plant essential oils and all treatments had significant difference compared to control except that of savory at $50 \mathrm{ppm}$ which was statistically similar with the control $(\mathrm{p}=$ $0.01)$. With the increase of concentrations, spore germination of the $B$. cinerea was significantly suppressed in such a way that both $100 \mathrm{ppm}$ and more concentration of wild marjoram and wild savory essential oils completely (100\%) stopped the spore germination of the fungus and no germ tube was observed (Table 3 and Fig. 3).

Table 2. Tested medicinal plants and their main compounds

\begin{tabular}{lll}
\hline Name of medicinal plant & Scientific name & \% of main compounds \\
\hline Wild marjoram & Zataria multifolia & Thymol: 31.10, Carvacrol: 27.49 \\
Wild savory & Satureja mutica & Thymol: 4.04, Carvacrol: 44.10 \\
Savory & Satureja hortensis & Thymol: 0.66, Carvacrol: 50.46 \\
\hline
\end{tabular}

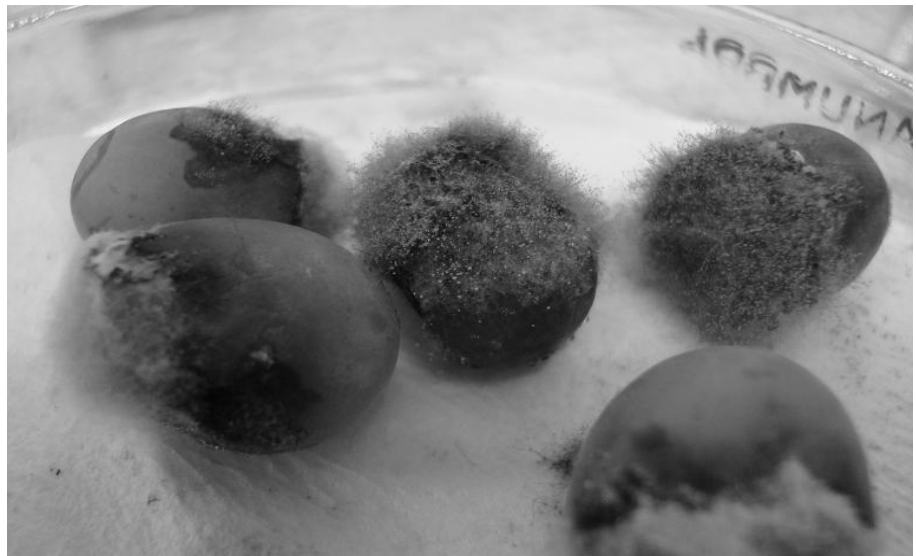

Figure 1. Growth of $B$. cinerea on grape berries (Var. Askari) during pathogenicity test 

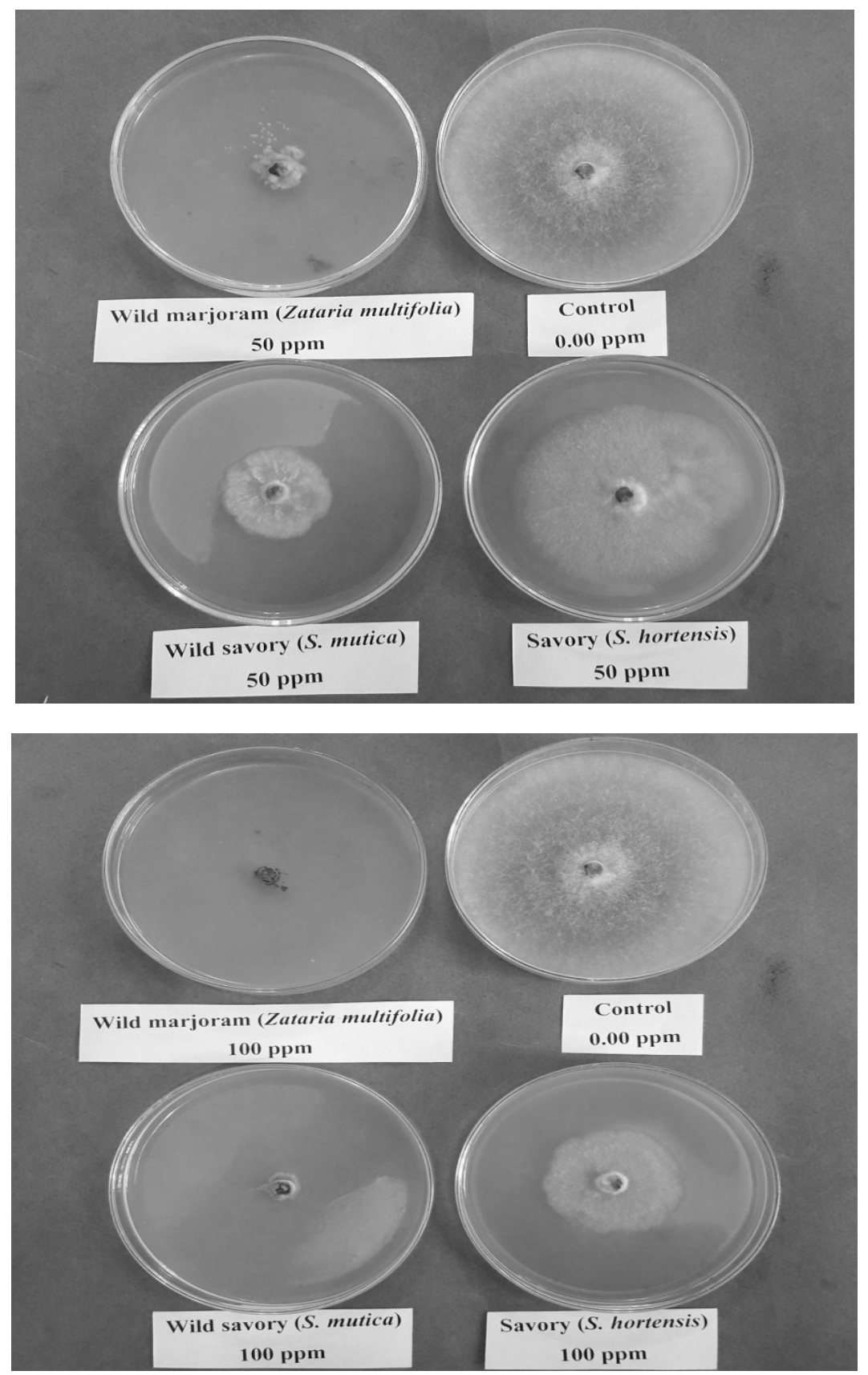

Figure 2. Effect of different essential oil concentrations on mycelial growth of B. cinerea compared to control 


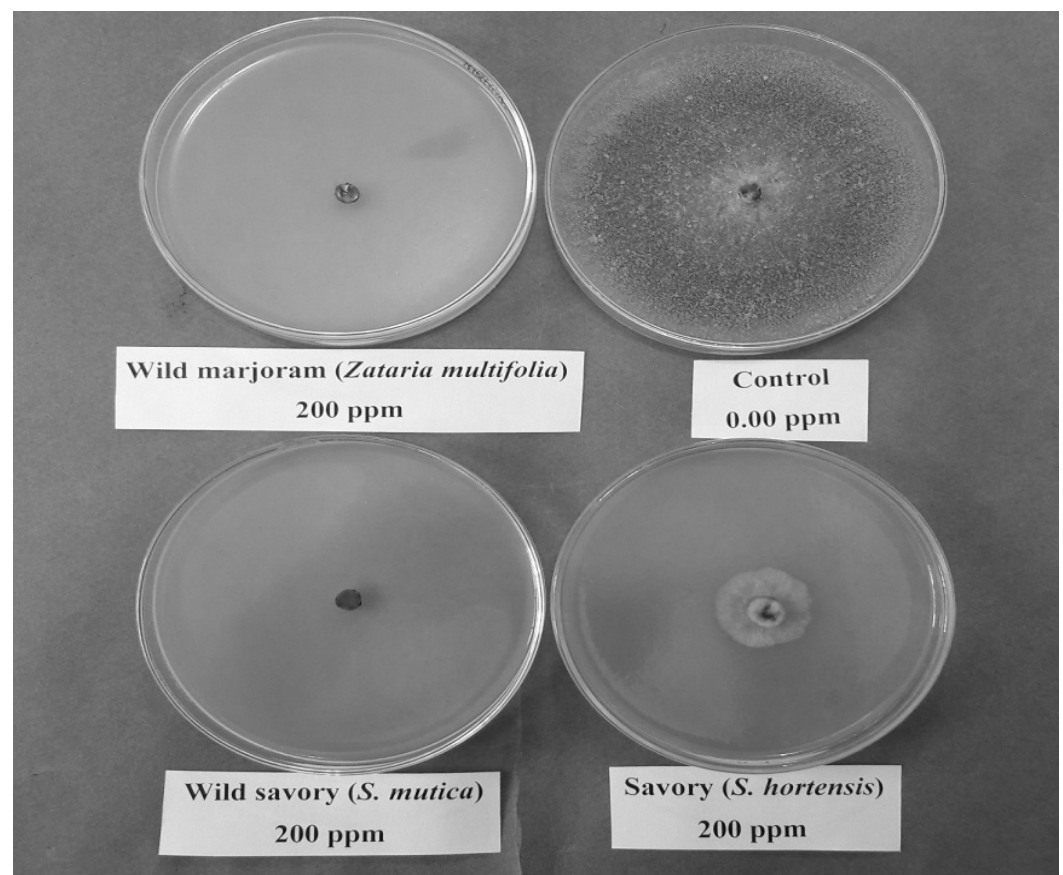

Figure 2 (continued). Effect of different essential oil concentrations on mycelial growth of B. cinerea compared to control
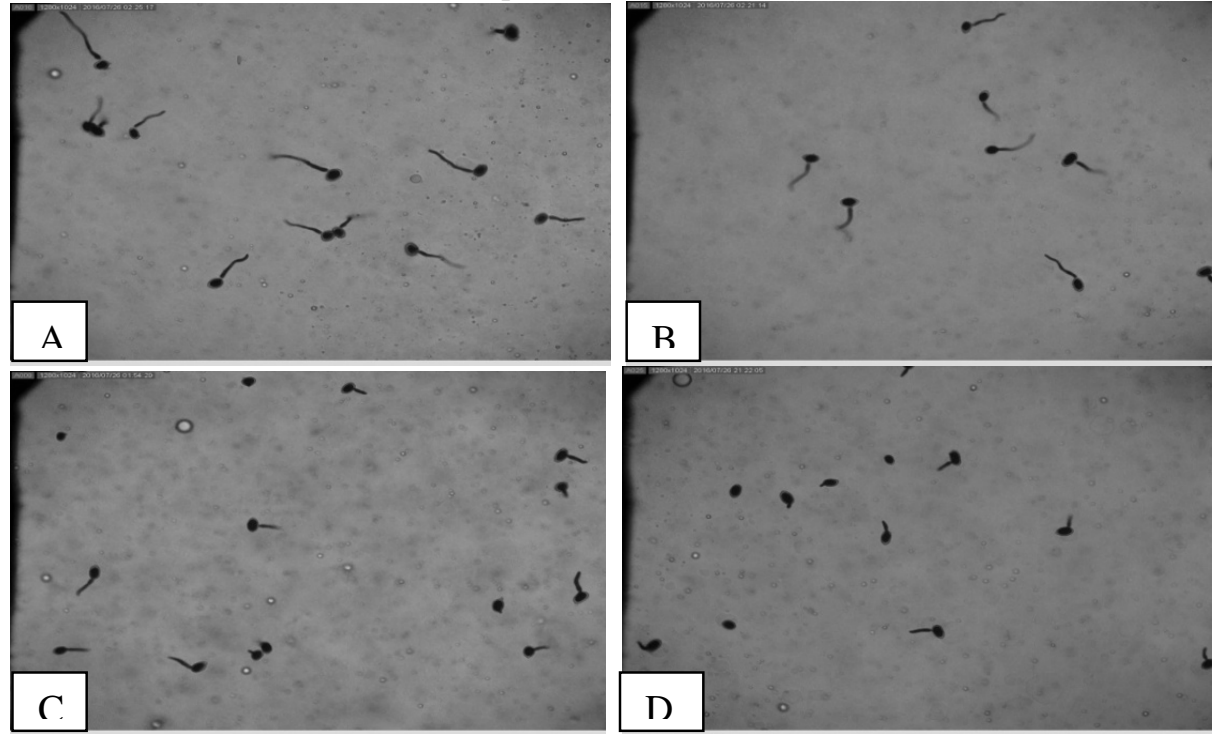

Figure 3. Effect of different essential oil concentrations (50, 100 and 200 ppm respectively) on spore germination and germ tube elongation of $B$. cinerea in PDA compared to control (magnification at 300 $\mathrm{X})$ : A, B and C (savory), D, E and F (wild savory), G, H and I (wild marjoram) and J (control) 

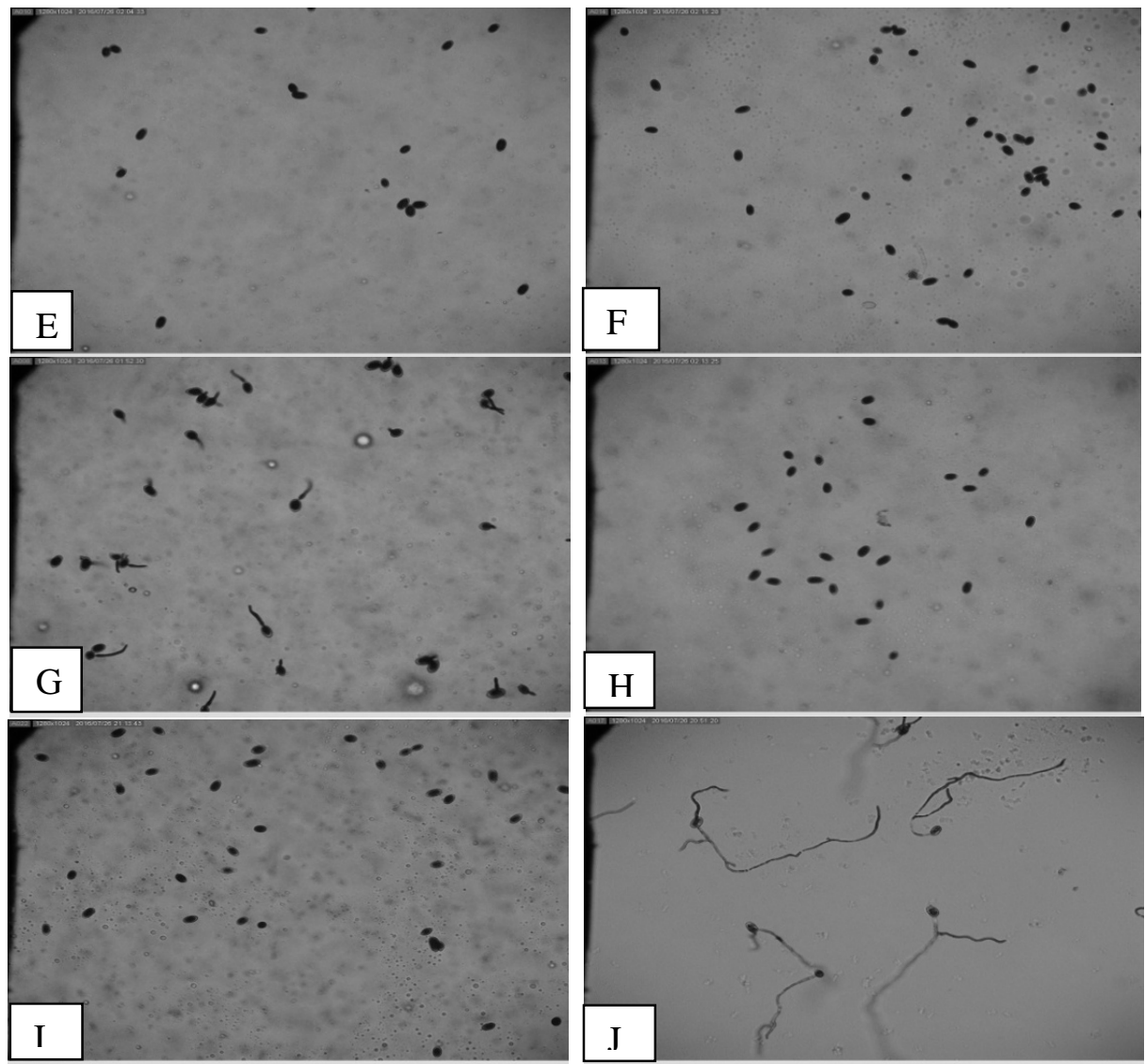

Figure 3 (continued). Effect of different essential oil concentrations (50, 100 and $200 \mathrm{ppm}$ respectively) on spore germination and germ tube elongation of $B$. cinerea in PDA compared to control (magnification at $300 \mathrm{X}$ ): A, B and C (savory), D, E and F (wild savory), G, H and I (wild marjoram) and $\mathrm{J}$ (control)

Table 3. Comparison of different treatments means as effect on mycelial growth, spore germination and germ tube elongation of $B$. cinerea

\begin{tabular}{lccc}
\hline Treatment & $\begin{array}{c}\text { Mean mycelial } \\
\text { growth }(\mathrm{cm})\end{array}$ & $\begin{array}{c}\text { Mean spore } \\
\text { germination }(\%)\end{array}$ & $\begin{array}{c}\text { Mean germ tube } \\
\text { length }(\mu)\end{array}$ \\
\hline Control & $9.00 \mathrm{a}$ & $100 \mathrm{a}$ & $114.4 \mathrm{a}$ \\
Savory -50 ppm & $8.56 \mathrm{a}$ & $100 \mathrm{a}$ & $44.68 \mathrm{~b}$ \\
Savory -100 ppm & $5.21 \mathrm{~b}$ & $75.00 \mathrm{~b}$ & $19.93 \mathrm{c}$ \\
Wild savory -50 ppm & $3.70 \mathrm{c}$ & $50.80 \mathrm{c}$ & $5.15 \mathrm{~d}$ \\
Savory -200 ppm & $2.40 \mathrm{~d}$ & $37.33 \mathrm{~d}$ & $7.33 \mathrm{~d}$ \\
Wild marjoram-50 ppm & $0.98 \mathrm{e}$ & $45.00 \mathrm{e}$ & $4.50 \mathrm{~d}$ \\
Wild savory -100 ppm & $0.81 \mathrm{e}$ & $0.00 \mathrm{f}$ & $0.00 \mathrm{e}$ \\
Wild marjoram-100ppm & $0.66 \mathrm{e}$ & $0.00 \mathrm{f}$ & $0.00 \mathrm{e}$ \\
Wild savory-200 ppm & $0.00 \mathrm{f}$ & $0.00 \mathrm{f}$ & $0.00 \mathrm{e}$ \\
Wild marjoram-200 ppm & $0.00 \mathrm{f}$ & $0.00 \mathrm{f}$ & $0.00 \mathrm{e}$ \\
\hline
\end{tabular}

Values in each column followed by the same letter are not significantly different $(P \leq 0.01)$ according to Duncan's multiple range test. 
The thymol and carvacrol were found to be effective against $B$. cinerea; this result was supported by previous research (Lee et al., 2007; Numpaque et al., 2011; Shin et al., 2014; Villanueva-Bermejo et al., 2015; Gavaric et al., 2015). These compounds could be used as effective antifungal compounds and can be safe alternatives for controlling a wide spectrum of microbial plant pathogens. The anti-microbial mechanism of these compounds are not well known but it is believed that such materials cause disorders in vital activity of fungal cell walls or destroy their cell walls (Isman and Machial, 2006).

Results of the current research showed that wild marjoram and wild savory containing more percentage of thymol and carvacrol compounds and had better antifungal activity against $B$. cinerea. These findings are in agreement with several works by Antonov et al. (1998) who reported that among several plant essential oils, thyme (Thymus capitatus) essential oil at $1 \%$ was the best in inhibiting $B$. cinerea of apple and even clove oil and oil of an Australian mint could not control it as such. Also Etemadi et al. (2012) stated that all three essential oils of Satureja hortensis, Zataria multiflora and Carum copticom at $200 \mathrm{ppm}$ and more were able to effectively control the growth of Botrytis mycelium on both PDA and the actual strawberries fruit. Findings of Shin et al. (2014) also showed that thymol antifungal activity was 4 times more than that of linalool in controlling the gray mold mycelium on table grapes because thymol at $30 \mu \mathrm{g} / \mathrm{mL}$ was equal to linalool at 120 $\mu \mathrm{g} / \mathrm{mL}$ in controlling the fungal mycelia. Other workers such as Mermer-Dogu and Zobar (2014) from Turkey and Sesan et al. (2015) from Romania also approved the effectiveness of these compounds in controlling $B$. cinerea the causal agent of horticultural products.

\section{Conclusions}

As essential oils produced from wild marjoram and wild savory had inhibitory effect against gray mold fungus (B. cinerea), therefore, their suitable formulations such as fumigants could be prepared and be used as safe alternatives to $\mathrm{SO}_{2}$ smoke for controlling molds of horticultural products in storage.

\section{Acknowledgement}

We are most grateful to Shahrood Agricultural Research Center authorities, Shahrood, Iran for their financial support to complete this research.

\section{References}

Adams R. P. 2007. Identification of essential oil components by gas chromatography/mass spectroscopy. Allured Publishing corporation. Carol stream. USA. 804pp.

Ahmadi K., Gholizadeh H., Ebadzadeh H. R., Hatami F., Hosseinpour R., Kazemifrd, R., Abdeshah, H. 2016. Agricultural data for the year 2014-2015. Horticultural products. $3^{\text {rd }} \quad$ Pub. Ministry of Agriculture. Center of information and communication technology. Tehran. Iran. 240 pp. (In Persian).

Antonov A., Stewart A., Walter M. 1998. Inhibition of conidium germination and mycelial growth of Botrytis cinerea by natural products. Journal of Food Microbiology, 23: 13-33.

Beever R. E., Weeds P. L. 2004. Taxonomy and genetic variation of Botrytis and Botryotinia. pp. 9-52 In: Botrytis, Biology, Pathology and Control, (Eds.) Y. Elad, B. Williamson, P. Tudzynski, N. Delen, Kluwer Academic Publisher. The Netherlands.

Behdani M., Pooyan M., Abbasi S. 2012. Evaluation of antifungal activity of some medicinal plant essential oils against Botrytis cinerea, causal agent of postharvest apple rot, in vitro. International Journal of Agriculture and Crop Sciences, 4(14): 1012-1016.

Elad Y., Williamson B., Tudzynski P., Delen N. 2007. Botrytis: Biology, Pathology and 
Control. Springer, The Netherlands. 393pp.

Etemadi N. A., Behdad M., Zeinali H. 2012. Antifungal effects of three plant essential oils against Botrytis cinerea: The cause of gray mold on strawberry. Journal of Research in Agricultural Science, 8(2): 165-170.

Fawcett C. H., Spencer D. M. 1966. Antifungal phenolic acids in apple fruits after infection with Sclerotinia fructigena. Annals of Applied Biology, 60: 87-96.

Gavaric N., Mozina S. S., Kladar N., Bozin B. 2015. Chemical profile, antioxidant and antibacterial activity of Thyme and Oregano essential oils, Thymol and Carvacrol and their possible synergism. Journal of Essential Oil Bearing Plants, 18(4): 1013-1021.

Ghafari Z., Kazemi-Ghahfarokhi N., Rahimi E. 2011. Presence of ochratoxin a in red and white grape juice commercialized in Iran. American-Eurasian Journal of Toxicological Sciences, 3(4): 228-230.

Isman M. B., Machial C. M. 2006. Pesticides based on plant essential oils: From traditional practice to commercialization. pp. 29-44 In: Naturally occurring bioactive compounds, (Eds) M. Rai, M. C. Carpinella, Elsevier, Amsterdam, The Netherlands.

Jalili-Marandi R., Hassani A., Ghosta Y., Abdollahi A., Pirzad A., Sefidkon F. 2010. Thymus kotschyanus and Carum copticum essential oils as botanical preservatives for table grape. Journal of Medicinal Plants Research, 4(22): 24242430.

Kritzman G., Netzer D. 1978. A selective medium for isolation and identification of Botrytis spp. from soil and onion seed. Phytoparasitica, 6: 3-7.

Lee S.O., Choi G. J., Jang K. S., Lim H. K., Cho K. Y., Kim J. C. 2007. Antifungal activity of five plant essential oils as fumigant against postharvest and soilborne plant pathogenic fungi. Plant Pathology Journal, 23(2): 97-102.

Mermer-Dogu D., Zobar D. 2014. Effects of some plant essential oils against Botrytis cinerea and Tetranychus urticae on grapevine. Turkish Journal of Agricultural and Natural Sciences. Special Issue 1: 1268-1273.

Numpaque M. A., Oviedo L. A., Gil J. H., García C. M., Durango D. L. 2011. Thymol and carvacrol: biotransformation and antifungal activity against the plant pathogenic fungi Colletotrichum acutatum and Botryodiplodia theobromae. Tropical Plant Pathology, 36 (1): 3-13.

Şesan T. E., Enache E., Iacomi B. M., Oprea M., Oancea F., Iacomi C. 2015. Antifungal activity of some plant extracts against Botrytis cinerea Pers. in the Blackcurrant crop (Ribes nigrum L.). Acta Sci. Pol., Hortorum Cultus, 14(1): 29-43.

Shin M. H., Kim J. H., Choi H. W., Keum Y. S., Chum S. C. 2014. Effect of Thymol and Linalool fumigation on postharvest diseases of table grapes. Mycobiology, 42(3): 262-268.

Siripornvisal S., Rungprom W., Sawatdikarn S. 2009. Antifungal activity of essential oils derived from some medicinal plants against grey mould (Botrytis cinerea). Asian Journal of Food and AgroIndustry. Special Issue, S229-S233.

Soylu E. M., Kurt S., Soylu S. 2010. In vitro and in vivo antifungal activities of the essential oils of various plants against tomato grey mould disease agent Botrytis cinerea. International Journal of Food Microbiology, 143(3): 183-189.

Villanueva-Bermejo D., Angelov I., Vicente G., Stateva, R. P., Rodriguez GarcíaRisco M., Reglero G., Ibañez E., Fornari T. 2015. Extraction of thymol from different varieties of thyme plants using green solvents. Journal of Science of Food and Agriculture, 95(14): 2901-290. 